\title{
"Obesity, Paternalism and Fairness"
}

\section{INTRODUCTION}

For many liberal theorists, the protection and promotion of population health is a requirement of justice. ${ }^{1,2,3}$ After all, each individual needs to be reasonably healthy to pursue her personal life plans, whatever these may be. But although the state must enable this pursuit, it is simultaneously limited by it: promoting population health only seems justifiable if this goal is compatible with the individual right to devise one's own idea of the good life. In other words, if a person attaches little value to her own health, forcing her to be healthy would appear to constitute an impermissible imposition of external values.

While this tension within liberalism arises in many public health contexts, the problem is especially salient in the case of obesity. As a significant risk factor for a host of chronic conditions - among them hypertension, type 2 diabetes and certain cancers - there is little doubt that obesity constitutes a major public health challenge. The drivers behind the rise of obesity are multifaceted, but public health interventions so far have centred on changing individual behaviours, above all overconsumption and physical inactivity. ${ }^{4}$ Assuming this is the most effective way to tackle the problem, the following normative question arises: when, if ever, may the state interfere with people's choices in order to make them change their unhealthy lifestyles?

I say that the problem is particularly salient because the negative effects of obesogenic behaviours appear to be limited to each individual in question. A contrast with recent successful attempts to regulate tobacco consumption may illustrate the point. Even though smoking too is an individual choice, the harms it causes are not merely self-regarding: passive smoking is a considerable risk to others. This makes bans, taxes and other restrictions of the right to smoke easier to justify, for, as the proverb goes, one person's freedom ends where another one's begins. The same does not seem to apply to the behaviours that lead to obesity, however.

My aim in this paper is to present a series of arguments in favour of liberty-restricting policies in the field of obesity prevention, and public health more generally. As I want to show, a "soft" form of paternalism, which interferes with people's choices to safeguard their true interests, goes some way in justifying such policies, but it leaves unaddressed 
the problem of limiting the liberty of those whose true interest is in pursuing an unhealthy lifestyle. I argue that in this case, the key to reconcile the promotion of population health with the respect for individual liberty is distributive justice: when we cannot help those who care about their health without doing the same for those who do not, fairness will often require us to do so.

\section{SOFT AND HARD PATERNALISM}

Let me begin by taking a closer look at the concept of paternalism. Liberals commonly accept that the state is at least sometimes justified in limiting a person's liberty for her own sake. As J.S. Mill famously allowed, we may forcibly prevent an unknowing passerby from crossing an unsafe bridge if there were no time to warn him of his danger. ${ }^{5}$ The idea here is that we are not interfering with the passer-by's ends, since we assume he does not want to fall into the river, but merely with his means. Thus if an individual's choice is clouded by ignorance, irrationality or other distorting factors it is non-voluntary - not genuine, as it were-and this might justify frustrating or preventing his choices to safeguard his true interests. If we lack knowledge of the latter, we interfere to protect that which any rational person would want: the preservation of life and health, among other things. If this sort of intervention is deemed paternalistic at all, it is generally welcomed as "soft" paternalism. 6

Now, this form of justification may be invoked in a wide array of liberty-restricting public health interventions, but certainly not all. For there will always be individuals who put their own health at risk voluntarily; out of their freely chosen and considered view that other things in life matter more to them. As Gerald Dworkin has incisively put it:

men are always faced with competing goods, and [...] there may be reasons why even a value such as health—or indeed life — may be overridden by competing values. Thus the problem with the Christian Scientist and blood transfusions. It may be more important for him to reject "impure substances" than go on living. The difficult problem that must be faced is whether one can give sense to the notion of a person irrationally attaching weights to competing values. (p. 78-9) $)^{7}$

The problem, then, is that some paternalistic interventions purport to save people not only from irrational or ill-informed means, but from ends which may strike others as somehow "mistaken," even though those who pursue them do so knowingly and willingly. This is 
the problem of "hard" paternalism. Can a liberal theory committed to the promotion of health support policies of this ilk without undermining its fundamental respect for individual liberty?

\section{IS IT A MISTAKE TO NEGLECT ONE'S HEALTH?}

Suppose a government debates three measures to reduce the incidence of obesity in society. "Fat tax 1 " is a tax on foods that contain a certain percentage of saturated fats. The second measure proposes to entirely ban particularly unhealthy products from the food supply. Finally "fat tax 2," a more fanciful measure, involves weighing citizens and taxing them if overweight. These measures are intrusive to varying degrees, and one might see them as lying along an "intervention ladder." 8 Yet all three may be motivated by hard paternalism so long as they not only interfere with the choices of people who compromise their health non-voluntarily, but also with those for whom an unhealthy diet forms part of the good life. Let us call the latter food lovers: their love for food is more important to them than their health.

Now, in order to justify hard paternalism, we would need to deny the validity of the food lover's life plan. The argument might run as follows. Even if the food lover is fully aware of the risks of her dietary habits, she makes a mistake if she cares too little about her health to change them. Sometimes people do not fully grasp the importance of their health until they lose it, at which point they are often willing to do almost anything to regain it. In contrast, many other values that we might pursue in our lives are very easy to appreciate, either because they are more tangible, because their rewards are more intense, or simply because we do not take them for granted in the same way. These considerations make evaluative delusions concerning health particularly likely, inviting paternalistic intervention.

As a psychological observation, these remarks are perfectly familiar. As an argument for hard paternalism, however, they rest on an invalid conflation of rationality and the good. To be sure, the propensity to weigh our values in favour of immediate gratification may be a form of cognitive bias or irrationality. This is what David Hume had in mind when he declared that there is "no quality in human nature which causes more fatal errors in our conduct than that which leads us to prefer whatever is present to the distant and remote." (p. 126) $)^{9}$ But note that if we neglect our health due to these flaws in our reasoning, we cannot say that our unhealthy lifestyle is truly voluntary. If this is case, most liberals will in principle accept some sort of soft paternalism to prevent us from 
inadvertently putting out health at risk.

And so the problem with hard paternalism remains. It is perfectly conceivable that a clear-headed person could truly prefer the immediate pleasures of feasting over long-term gains in health. The food lover may even be more rational than the one who foregoes all joy to stay in shape: if after all the future is uncertain, one may under certain conditions discount the future costs of an unhealthy lifestyle. ${ }^{10}$ Assuming voluntariness, then, the choice between feasting and longevity is simply a matter of taste. The conscious food lover might share our view about the value of health after suffering a heart attack. But then again, she might not. Hard though it seems to imagine that a long, healthy life is not her greatest priority, we should not force it upon her if it is not the life she wants to live.

The upshot is that (soft) paternalism may often be justified, but not with respect to the food lover, who (by definition) voluntarily embraces the health risks of her lifestyle. But does this then rule out any form of government interference with the food-lover's choices? In what follows, I want to argue that it does not. Liberals value not only individual liberty, but also equal liberty, meaning that the opportunities to pursue our own good must be fairly distributed throughout society. And thus, policies which on the face of it appear paternalistic toward the food-lover might in fact be motivated by something different altogether, namely a concern for fairness.

\section{OBESITY AND FAIRNESS}

The argument from fairness may come in different forms. One which regularly crops up in public discourse maintains that unhealthful behaviour is not always purely selfregarding. In the case of the food lover, it could be claimed that the bill for treating the medical needs that arise from her dietary habits is ultimately handed to the taxpayer. It is unfair, in this sense, that some must subsidise the expensive life plans of others. Yet while the argument has intuitive appeal, it is important to be aware of its limitations. First, much hinges on the particular empirical circumstances. Depending on how the healthcare system is financed, and what concrete risks the behaviours in question pose, it might well be that the costs to the public are negligible, or offset elsewhere. For instance, it is sometimes claimed that the costs of treating the medical needs of smokers and obese individuals are more than compensated by the social savings linked to their early deathsbe it in the healthcare system itself, or in other areas of social spending, such as the pension system. Error! Bookmark not defined.11,12

Second, if the argument is not applied consistently, we may doubt that avoiding harm 
to others is the real motivation behind our liberty-restricting intervention. Take the "fat tax 2" mentioned above. It wouldn't be hard to see herein a thinly veiled attempt to impose external values on obese people, that is, to "make them pay" for giving in to "gluttony" and "sloth." After all, we seem less inclined to push an argument for fairness in the distribution of healthcare costs when it comes to behaviour that is not considered "sinful." As Daniel Wikler points out, "skiing and football produce injuries as surely as sloth produces heart disease; and the decision to postpone childbearing until the thirties increases susceptibility to certain cancers in women." (p44) $)^{12}$ While the argument for taxing risky behaviour may be sound in principle, the burden of proof in our case is high: not only must it be shown that the food lover imposes considerable and unwarranted costs on society, but that our intervention merely seeks to compensate these costs, rather than force external values on her.

So let me turn to a different argument from fairness; one which may be less popular, but I think generally more relevant. We have thus far focused on the figure of the voluntary food lover, but clearly there are others who do not consciously embrace the health risks that their lifestyles pose. This might be due to a wide range of reasons. For example, some people are not appropriately informed about healthful nutrition, say, because state-sponsored attempts to educate the public are effectively dwarfed by corporate advertisement. ${ }^{13}$ Or-in line with recent evidence which conceptualises overeating as an addiction disorder ${ }^{14,15}$ - they might compulsively binge on comfort food as a reaction to high levels of stress. Or yet again, they might lack the ability to rationally assess the costs and benefits of a given behaviour: though they know that sodas are unhealthy, they cannot estimate the cumulative effect of their daily consumption.

Needless to say, there is great vagueness as to when an individual has voluntarily adopted a behaviour or lifestyle. The issue is particularly thorny because all our preferences and desires are to some extent shaped by circumstances which we have not freely chosen, such as our upbringing and social environment. The distinction between voluntariness and non-voluntariness must therefore be one of degree and not kind. But the problem of drawing a clear line should not concern us here, for just as surely as there are conscious food lovers there are also individuals whom we might dub non-voluntary overeaters. It is reasonable to assume that there is a large number of the latter, and further that their proportion will be greatest among the least advantaged members of society, reflecting inequalities in education and information. As the empirical literature shows, obesity and its behavioural causes are patterned along a socio-economic gradient, so that 
indeed quite often "poor people behave poorly."16

Now, the point I wish to make is the following. Freedom in self-regarding matters, as Richard Arneson has noted, tends to yield better results for those who are better positioned to choose among unrestricted options. ${ }^{17}$ This in itself would perhaps not be unfair, if everyone were skilled enough to make their choices reflect their genuine ends, or if this ability were randomly distributed in society. But as things stand, it is more plausible to think that the eschewal of liberty-restricting public health interventions would be particularly disadvantageous for the worst-off members of society. And so, if we cannot protect the non-voluntary overeater's health through soft paternalism, without thereby also restricting the liberty of the conscious food lover, fairness might require doing so.

True, in theory it would always seem preferable to tailor our interventions exclusively to the non-voluntary overeater, or to rely on non-restrictive measures altogether. For example, health education campaigns, or warnings issued on food packaging, aim to help the non-voluntary overeater, while requiring no further action from the food lover. Yet this might prove ineffective in practice. Not only are these campaigns, taken by themselves, unlikely to break existing patterns of addiction. The evidence also suggest that they work well for individuals of high socio-economic status, but less so for disadvantaged social groups, where the proportion of non-voluntary overeaters in need of protection is presumably greatest. ${ }^{8}$

Policies which target non-voluntary overeaters without affecting the conscious food lovers face a further problem. How are we to decide, on an individual level, who falls into which respective group? One could imagine subjecting all obese individuals to a psychological test to determine whether their dietary and exercise habits are truly voluntary. In a second step, some form of "fat tax" is levied on those who fail the test. But not only is it hard to imagine a practicable way to implement the voluntariness test, it also seems highly demeaning to single out individuals in this way: as public recognition of someone's lack of self-direction it would surely deal a blow to their self-respect. ${ }^{17}$

In this light, interventions of a more universalistic character seem more attractive, even when they restrict the liberty of those who are not legitimate targets of (soft) paternalism. "Fat tax 1," for instance, does not distinguish between food lovers and non-voluntary overeaters-in fact, it does not even distinguish between obese and non-obese individuals. And if even "fat tax 1" fails to have a positive impact on the non-voluntary overeater's dietary habits, increasingly restrictive measures might be justified. Maybe the sale of certain foods with particularly high fat, sugar or salt contents could be prohibited 
tout court, rather than merely taxed. Of course, the adequacy of such interventions will depend on the particular circumstances, but what is important to see here is the underlying justification: the choices of the food lover are not frustrated for her own sake, but instead to enable us to engage in soft paternalism towards the non-voluntary overeater.

\section{TWO OBJECTIONS}

The argument, in short, is that we must balance the interests of those who are legitimate paternalistic subjects against those who are not. In doing so, clearly several factors will be relevant - perhaps most obviously the proportion of people who fall into one group or the other, and the weight of their respective interests. Much work remains to be done in defining fine-grained criteria for the justifiability of liberty-restricting interventions in such mixed groups. ${ }^{18}$ The general point, however, is that often reasons of fairness will tip the balance in favour of those who would profit from the intervention; in particular when they are disproportionately among the worst off members of society in the first place.

Now, someone might object that what justice demands are not liberty-restricting measures, but rather changes to the social conditions that create the need for these measures. Assuming social disadvantage explains why many people become nonvoluntary overeaters, should we not aim at making society more just, instead of simply restricting their choices? While the reasoning behind this objection is sound, it should be noted that under non-ideal conditions, liberty-restricting interventions may in themselves be a way to eliminate disadvantage. As Norman Daniels notes, "some public-health measures, such as water and waste treatment, have the general effect of reducing risk. But historically, they have also had the effect of equalizing risk between socio-economic classes and between groups living in different geographical areas" (p. 142). ${ }^{1}$ The same can be said about public health risks which are based on lifestyles, such as smoking and obesity. In short, to reduce the inequalities in health which lead to unequal opportunities in life, we cannot do without effective public health policy.

But this leads us to a second, more fundamental objection. Allowing the food lover to live her live unhindered is more important than helping the overeater, someone might argue, because fairness should never trump liberty. One might here point to the priority of liberty, as defended even by egalitarians like John Rawls, ${ }^{19}$ or insist that refraining from harm (to the food lover) must always take precedence over conferring benefits (to the overeater). But this objection relies on a misconception. If the promotion of population health is indeed required by justice, then we are not simply in the business of conferring 
benefits or increasing social utility. Rather, we face the problem of ensuring a fair distribution of people's opportunities to pursue their good, so that the food lover's freedom to feast competes with the overeater's freedom lost through premature mortality and heightened morbidity. And from an impartial perspective, there may well be reasons to give priority to the opportunities of those who are already among the worst off. If the fate of the overeater is linked to that of the food lover in the ways I described, perhaps the case of obesogenic behaviour is more similar to that of smoking than initially appeared: one person's liberty is constrained by that of another.

Now to be sure, there is always a strong presumption against all state interference with individual choice. But there is also an important difference between, say, restricting freedom of expression and limiting the range of sodas available at the shop. Not all interests we might have deserve to be protected by basic rights. And so, the more is at stake for the overeater, the weightier the food lover's interest must be to rule out any restriction of her liberty. Without a doubt there are certain restrictions which may never be imposed on the food lover, no matter how important for the overeater. But on the whole, the argument from fairness may go a long way in providing a foundation for many interventions of the sort we discussed.

\section{CONCLUSION}

My goal in this paper has been to explore a tension between a justice-based rationale for the promotion of population health, and the value of individual liberty. Preventive public health policy must play an important role within a liberal theory of justice, but in seeking to improve health across society, we risk being unjustifiably paternalistic towards those who reject these benefits. I have sought to relieve this tension by arguing that (hard) paternalism is not defensible with regard to those who genuinely attach little value to their own health. Health should be treated as an instrumental good for the pursuit of individual life plans, and by this standard there is nothing that can be said to the individual whose life plan does not set much store by health. However, liberty-restricting public health interventions, which may at first glance look paternalistic towards these individuals, can be justified on other, non-perfectionist grounds. I highlighted an argument which deserves special attention: if we cannot protect the health of the worst off without interfering with the liberty of those who reject our intrusion on principle, there might be reasons of fairness to do so. Not only is this not inconsistent with our liberal premises, it follows directly from them. The freedom of some individuals must be weighed against the 
promotion of the social conditions which enable the freedom of others.

\section{REFERENCES}

${ }^{1}$ Daniels N. Just health: meeting health needs fairly. New York: Cambridge University Press, 2007.

${ }^{2}$ Barry B. Why Social justice matters. Cambridge: Polity Press, 2005.

3 Sen A. Why health equity? Health Econ 2002; 11/8: 659-66.

${ }^{4}$ Government Office for Science. Foresight report. Tackling obesity: future choices. London: Government Office for Science, 2007.

${ }^{5}$ Mill J.S. On liberty. New York: Penguin, 1986.

${ }^{6}$ Feinberg J. Harm to self. New York: Oxford University Press, 1986.

${ }^{7}$ Dworkin G. Paternalism. Monist 1972: 56/1: 64-84.

${ }^{8}$ Nuffield Council on Bioethics. Public health. Ethical issues. London: Nuffield Council on Bioethics, 2007.

${ }^{9}$ Hume D. Moral philosophy. Indianapolis: Hackett publishing, 2006.

${ }^{10}$ LeGrand J. Individual responsibility, health, and health-care. In: Eyal N, Hurst S and Norheim O, eds. Inequalities in health. Concepts, measures, and ethics. New York: Oxford University Press, 2013: 299306.

${ }^{11}$ Van Baal P, Polder J, De Wit G, et al. Lifetime medical costs of obesity: prevention no cure for increasing health expenditure. Plos Med 2008; 5/2: e 29.

${ }^{12}$ Wikler D. Persuasion and coercion for health: ethical issues in government efforts to change lifestyles. Milbank Q 1978; 56/3: 303-38.

${ }^{13}$ Brownell K, Warner K. The perils of ignoring history: Big Tobacco played dirty and millions died. How similar is Big Food? Milbank Q 2009; 87/1: 259-94.

${ }^{14}$ Davis C, Carter J. Compulsive overeating as an addiction disorder. A review of theory and evidence. Appetite 2009; 53: 1-8.

${ }^{15}$ Kalivas $\mathbf{P}$, Volkow $\mathbf{N}$. The neural basis of addiction: a pathology of motivation and choice. Am J Psych 2005; 162:1403-13.

${ }^{16}$ Lynch J, Kaplan G, Salonen J. Why do poor people behave poorly? Variation in adult health behaviours and psychosocial characteristics by stages of the socioeconomic life course. Soc sci \& med 1997; 44/6: 809-819.

${ }^{17}$ Arneson R. Paternalism, utility and fairness. Rev int philos 1989; 43/170: 409-37.

${ }^{18}$ Grill K. Liberalism, altruism and group consent. Public health ethics 2009; 2/2: 146-57.

${ }^{19}$ Rawls J. A theory of justice. Cambridge MA: Harvard University Press, 1999. 